\section{Posible efecto protector de Helicobacter pylori contra la diarrea infantil}

Se ha observado una relación inversa entre la colonización por Helicobacter pylori y la enfermedad diarreica en niños. Según los resultados de un estudio poblacional reciente, es posible que $H$. pylori confiera protección contra las infecciones gastrointestinales que producen diarrea. Algunos estudios anteriores han demostrado que esta bacteria se asocia con una proliferación de las células de la mucosa gástrica que secretan inmunoglobulina $\mathrm{A}$ y con la secreción de péptidos antibacterianos, mecanismos que protegen al individuo contra la colonización por otros tipos de bacterias. En el estudio reciente, que se llevó a cabo en la ciudad de Ulm, en el sur de Alemania, los autores investigaron si la tasa de diarrea se veía afectada por la ausencia o presencia de infección por $H$. pylori en 2477 niños de 5 a 8 años. Los investigadores, utilizando una prueba de aliento para la detección de urea marcada con carbono $13\left({ }^{13} \mathrm{C}\right)$, encontraron que $12,3 \%$ de los niños estaban infectados por $H$. pylori. De estos niños, 54,3\% habían padecido un episodio de diarrea en los 3 meses anteriores; en cambio, 76,1\% de los que no estaban infectados por $H$. pylori habían tenido diarrea durante ese período. Tras hacer ajustes para compensar el efecto de las covariables, los investigadores calcularon una razón de posibilidades (odds ratio) de 0,56 de sufrir diarrea en el grupo infectado.

Los autores llegan a la conclusión de que los beneficios que aporta la colonización por H. pylori podrían superar los riesgos, ya que relativamente pocos portadores de $H$. pylori llegan a tener síntomas provocados por la bacteria en el transcurso de la vida. La conocida asociación de $H$. pylori con la aparición de úlcera péptica y adenocarcinoma gástrico se limita a la población adulta. Si los resultados del presente estudio se confirman mediante otras investigaciones, podrían cambiar radicalmente las estrategias terapéuticas y preventivas, especialmente en niños que viven en países en desarrollo, donde la enfermedad diarreica es una de las principales causas de mortalidad en la población infantil. (Rothenbacher D, Blaser MJ, Bode G, Brenner $H$. Inverse relationship between gastric colonization by Helicobacter pylori and diarrheal illnesses in children: results of a population-based cross-sectional study. J Infect Dis 2000;182(5):1446-1449.)

\section{El consumo de calcio y fibra en la dieta y el riesgo de sufrir pólipos intestinales}

En un estudio efectuado en Europa, se investigó si la suplementación de la alimentación con calcio afecta a la recurrencia de tumores benignos del colon y el recto, que a menudo son lesiones precancerosas. Los investigadores distribuyeron al azar en tres grupos terapéuticos diferentes a 665 pacientes con antecedentes de pólipos benignos intestinales o rectales. Un grupo recibió un suplemento diario de dos gramos de calcio; el segundo recibió 3,5 gramos de fibra soluble y el tercero, placebo. Al cabo de tres años, había tenido un mínimo de un pólipo benigno $16 \%$ del grupo tratado con calcio, $29 \%$ del grupo que ingirió fibra y $20 \%$ del grupo que recibió placebo. Esto significa que las personas que ingirieron la dieta rica en fibra mostraron mayor propensión a tener pólipos recurrentes que las que recibieron placebo. El efecto beneficioso del calcio en comparación con el placebo no se consideró estadísticamente significativo.

Este es el primer estudio que investiga los efectos en el ser humano de la planta mucilaginosa conocida por Plantago psyllium o zaragatona, que puede prevenir el cáncer de colon en animales. Cabe recordar, sin embargo, que el estudio se ve limitado por varios factores. El primero es el hecho de que 113 participantes no completaran el total de 3 años de observación establecido y de que la muestra final fuera menor de la anticipada, que era de 1200 personas. En segundo lugar, es muy difícil comparar los resultados obtenidos en los 10 países que participaron en el estudio debido a diferencias muy patentes en la manera de calcular la ingestión de alimentos. Es posible, además, que los participantes no hayan notificado con exactitud el consumo de frutas y legumbres, que se investigó mediante un formulario escrito. Por último, las personas que recibieron suplementos de calcio no siempre los tomaron según se había prescrito, quizá porque algunas de las que ya consumían una dieta rica en calcio tuvieron reacciones adversas.

En resumen, estos resultados llevan a la conclusión de que las personas con antecedentes de pólipos del colon o recto no necesariamente pueden prevenir la aparición de nuevos tumores mediante la ingestión de una dieta rica en fibras más la adición de suplementos fibrosos a la alimentación. No obstante, los autores recomiendan el consumo de 
legumbres, frutas y cereales por su efecto protector contra los trastornos cardiovasculares y otras enfermedades crónicas. (Bonithon-Kopp C, Kronborg O, Giacosa A, Räth U, Faivre J, for the European Cancer Prevention Organisation Study Group. Calcium and fibre supplementation in prevention of colorectal adenoma recurrence: a randomised intervention trial. Lancet 2000;356(9238):1300-1304).

\section{Relación entre salud materna e intervalo entre embarazos}

El riesgo de diversos trastornos perinatales, como el bajo peso al nacer, la muerte neonatal y el parto prematuro, parece verse aumentado por un intervalo demasiado corto o demasiado largo entre embarazos. Hay menos datos acerca del efecto que tiene en la morbilidad y mortalidad maternas el intervalo entre gestaciones. En un estudio muy extenso efectuado por Eastman en 1944 en una muestra de 5158 mujeres, no se detectó ninguna asociación entre dicho intervalo y la anemia materna, la hemorragia posparto, la fiebre del puerperio y la mortalidad materna. Se observó un riesgo aumentado de toxemia conforme aumentaba el intervalo entre embarazos. En este estudio, sin embargo, no se hicieron ajustes para compensar el efecto de factores de confusión y hubo pocas mujeres con intervalos cortos entre gestaciones. Otros dos estudios de casos y testigos efectuados en fecha más reciente han arrojado resultados contradictorios en cuanto a la relación entre mortalidad materna y el espaciamiento entre embarazos. La base de datos del Sistema de Información Perinatal Latinoamericano y Caribeño de Montevideo, Uruguay, que contiene datos sobre las características sociodemográficas de la madre y los resultados gestacionales, ofreció una oportunidad para estudiar los efectos del intervalo entre embarazos en la morbilidad y mortalidad maternas.

En el estudio, retrospectivo y transversal, se incluyeron 456889 mujeres que ya habían tenido un niño vivo o un mortinato con más de 19 semanas de gestación como resultado de un embarazo simple. Las principales variables de interés fueron las siguientes: muerte materna, preeclampsia, eclampsia, diabetes mellitus de origen gestacional, hemorragia durante el tercer trimestre, ruptura prematura de las membranas, hemorragia posparto, endometritis puerperal y anemia materna. Para cada una de estas variables se calcularon las razones de posibilidades (odds ratio) brutas y ajustadas. Se observaron intervalos cortos (<6 meses) y largos ( $>59$ meses) entre embarazos en 2,8 y $19,5 \%$ de las mujeres estudiadas, respectivamente. Después de hacer ajustes para compensar la influencia de los principales factores de confusión, se encontró que, en comparación con las mujeres con intervalos de 18 a 23 meses entre gestaciones, aquellas cuyos intervalos eran de 5 meses o menos corrían un mayor riesgo de muerte materna (RP: 2,54; IC95\%: 1,22 a 5,38), hemorragia durante el tercer trimestre (RP: 1,73; IC95\%: 1,42 a 2,24), ruptura prematura de las membranas (RP: 1,72; IC95\%: 1,53 a 1,93), endometritis puerperal (RP: 1,33; IC95\%: 1,22 a 1,45) y anemia (RP: 1,30; 1,18 a 1,43). Al comparar a las mujeres con intervalos de 18 a 23 meses entre gestaciones con aquellas cuyos intervalos eran de 59 meses como mínimo, se halló que estas últimas tenían un riesgo notablemente mayor de sufrir preeclampsia (RP: 1,83; IC95\%: 1,72 a 1,94) y eclampsia (RP: 1,80; IC95\%: $1,38$ a 2,23$)$.

La conclusión que se desprende de este estudio es que tanto un intervalo intergestacional menor de 6 meses como uno mayor de 59 meses se asocia con un mayor riesgo de morbilidad y mortalidad maternas. (Conde-Agudelo A, Belizán JM. Maternal morbidity and mortality associated with interpregnancy interval: cross sectional study. BMJ 2000;321: 1255-1259).

\section{¿Es beneficiosa la dosis de refuerzo de la vacuna contra Haemophilus influenzae?}

La vacuna conjugada contra Haemophilus influen$z a e$ tipo b (Hib) protege a los niños contra uno de los principales agentes causales de enfermedades peligrosas, como la meningitis, septicemia, pneumonía y epiglotitis. Muchos países han adoptado las vacunas conjugadas contra $\mathrm{Hib}$ con resultados sumamente favorables. El régimen recomendado, similar al que se aplica a otras vacunas contra enfermedades de la infancia, como la DTP (difteria, tétanos, tos ferina) y la vacuna antipoliomielítica, consiste en la administración de tres dosis (a los 2, 3 y 4 meses de edad) más una dosis de refuerzo durante el segundo año de vida. Esta dosis de refuerzo, por razones económicas, solamente ha sido adoptada por algunos países desarrollados, pero según los resultados de un estudio reciente que se llevó a cabo en el Reino Unido, se trata de una dosis que no aporta ningún beneficio adicional.

Los investigadores compararon las concentraciones de anticuerpos protectores contra $H$. influenzae en la sangre de 153 niños vacunados a las edades recomendadas con las de niños que habían recibido una dosis de refuerzo entre los 43 y 72 meses de edad. Según los resultados, la eficacia de la vacuna se reduce después del primer año $(P<0,001)$, pero en términos generales se conserva bastante alta 
hasta el sexto año de vida $(99,4 \%$ en niños de 5 a 11 meses y $97,3 \%$ en niños de 12 a 71 meses de edad). Aunque la cuarta dosis no tiene ningún efecto nocivo en los niños que la reciben, se trata de una inyección muy cara y a menudo dolorosa. En el estudio también se examinó de manera prospectiva, durante el período de octubre de 1992 a marzo de 1999, la tasa de infección invasora por $H$. influenzae en los 4368200 niños que habían recibido las tres dosis de vacuna prescritas por el régimen vigente en el Reino Unido. Se encontró una tasa de fracaso de 2,2 por cada 100000 niños vacunados (IC95\%: $1,8$ a 2,7$)$.

La conclusión de que la dosis de refuerzo en el segundo año de vida es innecesaria tiene grandes consecuencias para aquellos países que aún no han iniciado la vacunación de rutina contra Hib. En gran parte del mundo en desarrollo, las infecciones por Hib cobran gran número de vidas infantiles, pero pocos de estos países tienen los recursos económicos para pagar una vacuna tan costosa. La decisión de adoptar el régimen de vacunación contra Hib se vería facilitada si hicieran falta menos dosis. De hecho, Chile acaba de dar un paso en esa dirección con la adopción de la vacuna conjugada contra Hib siguiendo un esquema de tres dosis. Se espera que la eliminación de la dosis de refuerzo impulse a otros países latinoamericanos a seguir el ejemplo de Chile. (Health PT, Booy R, Azzopardi HJ, Slack ME, Path FRC, Bowen-Morris J, et al. Antibody concentration and clinical protection after Hib conjugate vaccination in the United Kingdom. JAMA 2000;284(18):2334-2340).

\section{Mecanismos de inhibición de la respuesta inmunitaria por algunos agentes patógenos}

Yersinia pestis es el agente causal de la peste bubónica y peste pneumónica que azotaron al Viejo Mundo durante la Edad Media y que en apenas cinco años cobraron la vida de más de la tercera parte de la población de Europa. La peste, que se originó en Asia y penetró en Europa en 1347 por las rutas de intercambio comercial, llegó en una época de malas cosechas en que los pobres tenían poca resistencia contra la enfermedad. Debido a su impacto decisivo en la religión, la economía, la política, las relaciones sociales y la vida familiar, cabe afirmar que la peste cambió el rumbo de la historia europea.

Un grupo de investigadores dedicado al estudio de $Y$. pestis y de los virus que causan el catarro común y diversas enfermedades de las plantas acaba de descubrir un mecanismo que estos microorganismos utilizan para inhibir el sistema inmuni- tario del huésped e impedir que monte una defensa contra las infecciones. El hecho de que los tres organismos estudiados muestren características muy diferentes refuerza la sospecha de que se trata de un mecanismo que muchas bacterias y virus tienen en común. Este descubrimiento podría servir para elaborar nuevos medicamentos contra enfermedades tan diversas como el resfriado común y la peste bubónica, de la cual sigue habiendo brotes en la India y otras partes del mundo en desarrollo, o contra los microorganismos que arruinan las cosechas. Se especula que estos resultados podrían arrojar luz sobre los mecanismos de comunicación entre células cancerosas e incluso llevar al descubrimiento de fármacos que impidan el crecimiento de los tumores.

Las especies de Yersinia poseen un plásmido de 70 kilobases que codifica un sistema secretor tipo III y diversas proteínas efectoras conocidas por Yops (Yersinia outer proteins). Estas Yops son transferidas de la bacteria a las células del huésped, donde alteran las estructuras que ejercen una función crítica en la emisión de las señales que impiden la fagocitosis y la inducción de la respuesta inmunitaria. Una de las proteínas efectoras, conocida por YopJ, inhibe la respuesta inmunitaria al prevenir la activación, por medio de la fosforilación, de la vía de la monoaminfosfocinasa (MAPK), así como la producción de citoquinas y la activación de los factores que impiden la apoptosis celular.

Los descubridores del mecanismo inhibidor de la respuesta inmunitaria ya han elaborado un medicamento contra la enzima vírica que ha dado buenos resultados en estudios in vitro con adenovirus, pero aún no se sabe si este medicamento tendrá eficacia contra bacterias y otros microorganismos. En todo caso, una compañía farmacéutica ya ha empezado a negociar una licencia de comercialización y se espera que pronto otras manifiesten el mismo interés. (Orth K, Xu Z, Mudgett MB, Bao ZQ, Palmer LE, Bliska JB, et al. Disruption of signaling by Yersinia effector YopJ, a ubiquitin-like protein protease. Science 2000;290(5496):1594-1597).

\section{Estado deplorable de la higiene en el mundo}

De acuerdo con los resultados de una evaluación efectuada por la OMS y el Fondo de las Naciones Unidas para la Infancia (UNICEF), casi la mitad de la población mundial carece de una infrasestructura higiénica adecuada. Y esta situación existe muy a pesar de los grandes esfuerzos de los dos últimos decenios por proporcionar a las poblaciones indigentes del mundo en desarrollo mejores servicios de higiene y abastecimiento de agua. Como resultado de la evaluación, la comunidad científica, re- 
presentada por 500 expertos en salud pública, higiene y saneamiento, hace un llamado al mundo entero para redoblar sus esfuerzos por mejorar las deplorables condiciones de higiene en que viven alrededor de 1,1 mil millones de personas.

La evaluación también arrojó los siguientes hallazgos:

- De los 4,9 mil millones de personas que tienen acceso a servicios de abastecimiento de agua, alrededor de 3 mil millones están conectados a una red domiciliaria dentro de la casa o en el patio.

- Anualmente se producen alrededor de 4 mil millones de casos de diarrea y 2,2 millones de defunciones por esta causa. Si las poblaciones afectadas tuvieran buenos servicios de higiene y saneamiento, la frecuencia de episodios de diarrea podría reducirse en una cuarta parte o más.

- Aunque los servicios de saneamiento en zonas rurales son muy inferiores a los de las zonas urbanas, siguen siendo enormes las dificultades de proveer servicios de saneamiento adecuados a una población urbana pobre que crece aceleradamente.

- Son abismales las diferencias entre la inversión para mejorar los servicios destinados a los sectores prósperos de la sociedad y los destinados a proveer los servicios más básicos a los sectores de escasos recursos.
Como se señala en la introducción al informe sobre la evaluación, el acceso a agua potable y a instalaciones higiénicas para la disposición de excretas es una necesidad e incluso un derecho de todo ser humano, por tratarse de elementos fundamentales del desarrollo y de la lucha contra la pobreza. Es, en otras palabras, un componente indispensable de la atención primaria de salud.

Además de los hallazgos señalados anteriormente, la evaluación también ha revelado que la tarifa que cobran las compañías de abastecimiento de agua en países en desarrollo no es suficiente para hacer frente a los costos de producción y de distribución. En la subregión de América Latina y el Caribe, la razón dada por tarifa:costo de producción es cercana a 0,9:1. Además, el tratamiento de las aguas residuales es práctica poco frecuente en países en desarrollo (14\% en América Latina), donde alrededor de $40 \%$ del agua se desperdicia antes de llegar al posible usuario, sobre todo en zonas marginales. Por otra parte, no toda el agua que se distribuye en las grandes ciudades es potable.

Los 500 expertos antedichos se reunieron en Brasil el 24 de noviembre para idear un programa de alcance mundial orientado a corregir esta situación y a reducir a la mitad para 2015 el número de personas que carecen de acceso a buenos servicios de saneamiento y agua potable. (World Health Organization. Almost half the world's people have no acceptable means of sanitation. Comunicado de prensa $\mathrm{WHO} / 73,22$ de noviembre de 2000).

Statistics of illness can afford an indication of vitality that it is not less biologically significant and is more illuminating than mortality. They portray the condition of a people's health far more delicately than death rates. They reveal the prevalence and incidence of disease in a population in a manner that is as useful to the student of society as clinical observation of the individual patient is to the physician.

[Las estadísticas de morbilidad pueden proporcionar indicios de vitalidad que no son menos significativos en un sentido biológico y que son más reveladores que la mortalidad. Representan las condiciones de salud de una población con mucha más sutileza que las tasas de defunción. Revelan la prevalencia e incidencia de enfermedades en una población de una manera que es tan útil para el observador de los fenómenos sociales como lo es la observación clínica del paciente para el médico.]

Edgar Sydenstricker "Statistics of morbidity" The Challenge of facts, 1994 